\title{
Approaching motor and language deficits in autism from below: a biolinguistic perspective
}

\author{
Antonio Benitez-Burraco ${ }^{1 *}$ and Cedric Boeckx ${ }^{2,3}$ \\ ${ }^{1}$ Department of Spanish Philology and its Didactics, University of Huelva, Huelva, Spain, ${ }^{2}$ Catalan Institute for Advanced \\ Studies and Research (ICREA), Barcelona, Spain, ${ }^{3}$ Department of Linguistics, Universitat de Barcelona, Barcelona, Spain
}

Keywords: ASD, motor deficits, language, speech, candidate genes, language-ready brain, externalization, vocal learning

\section{OPEN ACCESS}

Edited by:

Jennifer M. Groh,

Duke University, USA

Reviewed by:

Genevieve Konopka,

University of Texas Southwestern

Medical Center, USA

Erich David Jarvis,

Duke University Medical Center, USA

*Correspondence:

Antonio Benítez-Burraco, antonio.benitez@dfesp.uhu.es

Received: 15 January 2015 Accepted: 13 March 2015

Published: 30 March 2015

Citation:

Benítez-Burraco $A$ and Boeckx C (2015) Approaching motor and language deficits in autism from

below: a biolinguistic perspective.

Front. Integr. Neurosci. 9:25.

doi: 10.3389/fnint.2015.00025
In their paper "Oral motor deficits in speech-impaired children with autism" (Front. Integr. Neurosci. 7:47). Belmonte et al. (2013) argue that expressive language deficits in a subgroup of people with autism result from the impairment of the oromotor function. As a matter of fact, the paper appeared in a Frontiers Research Topic that brings movement to the forefront of autism research. Ultimately, this collection of papers aims to support the view that movement and cognition should be considered jointly if we want to properly diagnose and treat this condition, and that motor abnormalities may constitute a significant and robust endophenotype for autism spectrum disorders (ASD) (see Esposito and Paşca, 2013). At the same time, advances in genome-wide technology have yielded an increasing amount of genes related to autism, which point to specific mechanisms and pathways underlying its associated deficits (Jeremy Willsey and State, 2014). However, as pointed out by Jeste and Geschwind (2014) robust endophenotypes of the disorder based on these findings are still forthcoming and the gap between the pathophysiology of autism and genes still remains open. The goal of this commentary is to contribute to bridge this gap between genes and ASD, focusing specifically on motor dysfunction and language deficits in people with autism. In doing so, we will adduce considerations from the fields of the biology of language and of language evolution (aka Biolinguistics). We hope that steps of the sort we take will eventually help us better understand the comorbidity, heterogeneity, and variability of ASD, but also the biological underpinnings of the human faculty of language.

In our recent research (Boeckx and Benítez-Burraco, 2014a,b; Benítez-Burraco and Boeckx, submitted) we have put forth three set of genes that we think are important for the emergence of the two basic components of our species-specific capacity for acquiring and using a language, which we have labeled our "language-ready brain": our specific mode of cognition (namely, the ability to form cross-modular concepts), and our specific way of externalizing thoughts, usually in the form of strings of sounds. In the linguistic literature these two separated abilities are usually referred to as the syntax-semantics interface and the morphophonological component, respectively.

The first set of genes is centered around RUNX2, a gene involved in skull and brain development. According to our findings, the evolutionary modification of this network may account for our more globular head shape (compared to Neanderthals) and for the concomitant rewiring of different connections between cortical and sub-cortical (specifically, thalamic) structures, which provide the scaffolding for our species-specific mode of cognition (see Boeckx and Benítez-Burraco, 2014a for details). The second set is centered on the ROBO1 and FOXP2 interactomes, two genes that have been repeatedly associated to speech disorders, and which emerge from the literature as prominent molecular signatures of vocal learning and motor control (see Boeckx and BenítezBurraco, 2014b for details). The third set is clustered around AUTS2 and it provides additional robust links between the two main networks we have uncovered (see Benítez-Burraco and Boeckx, submitted for details). Many components of these three sets show fixed changes in modern humans 
compared to Neanderthals/Denisovans, which affect their regulatory regions, their coding regions, or both. Overall, we think that most of the genetic changes that brought about our language-readiness did not occur in a mosaic fashion, but rather revolved around changes in skull/brain morphology and neural connectivity that resulted in a more globular brain.

It is with this background in mind that we want to approach Belmonte et al.'s (2013) paper and ultimately, the motor perspective on language dysfunction in autism. What we have found is that many candidates for ASD belong to the three gene sets we believe are important for language development in the individual and in the species. For example, as part of our set centered on RUNX2 one finds CTNNB1 (O'Roak et al., 2012), HRAS (Comings et al., 1996), DLX1 (Liu et al., 2009), DLX5 (Nakashima et al., 2010), PTEN (Naqvi et al., 2000; Butler et al., 2005), and SMURF1 (De Rubeis et al., 2014), all potential ASD candidates. Similarly, one finds several candidates for ASD among the genes comprising the second set, centered on the FOXP2/ROBO1 interactomes, including ROBO2 (Suda et al., 2011), FOXP1 (Hamdan et al., 2010), POU3F2 (Lin et al., 2011), and CNTNAP2 (Alarcón et al., 2008). Finally, AUTS2 (Oksenberg and Ahituv, 2013) is a robust candidate for $\mathrm{ASD}$, and this is also the case with other genes that are functionally linked to it, like TBR1 (Deriziotis et al., 2014), FEZF2 (Wang et al., 2009), PAX6 (Maekawa et al., 2009) and SATB2 (Kwan, 2013).

When we move from genes to cellular function, we find that these three set of genes, and specifically the ones we just highlighted, regulate processes that are central in the pathophysiology of autism. Concerning the set centered on RUNX2, it is primarily related to skull morphogenesis, thalamic development and the specification, migration and interconnection of GABAergic neurons within the forebrain. Interestingly, autism sometimes entails deviations in head shape, resulting from deviations in brain growth and connectivity (Cheung et al., 2011). More importantly, aberrant development of GABAergic interneurons has been linked to ASD (Di Cristo, 2007). Lastly, autism usually involves the impairment of thalamocortical connectivity (Nair et al., 2013). The thalamus acts as an efficient mode of corticocortical connections that we deem necessary for cross-modularity and for going beyond stereotypical behaviors (see Boeckx and Benítez-Burraco, 2014a for details). Overall, given the role of this set of genes in language development and evolution, the fact that we find among them several autism-candidate genes may help explain the distinctive mode of cognition observed in people with autism, but also their problems with (receptive) language (e.g., Tager-Flusberg et al., 2005).

The thalamus also functions as a bridge between several cortical and subcortical components important for the externalization of language, as part of the so-called anterior pathway of vocal learning, which involves the basal ganglia (especially, the striatum) and the fronto-temporal network connecting Wernicke's and Broca's areas (Hickok and Poeppel, 2007; Miller and Buschman, 2007; Petkov and Jarvis, 2012). All these brain areas and neuronal networks show anomalies in ASD (e.g., Murphy et al., 2014). Specifically, tracts between the thalamus and the motor cortex are compromised in ASD, suggesting that the former region may play a role in motor abnormalities reported in this condition (Nair et al., 2013). Overall, the fact that we find several autism-candidate genes among the genes that are related to the externalization of language may explain why speech problems are frequently observed in people with autism. As noted by Wang et al. (2015) this may be due to the involvement of the ROBO proteins and their ligand SLITs, which play a central role in the organization of the specialized forebrain circuits that control vocal learning, specifically, the forebrain part that connects to brainstem vocal motor neurons (Wang et al., 2015), and which points to convergent molecular changes in all vocal learners (Pfenning et al., 2014). The involvement of FOXP2 and its partners makes this link even more robust and more interesting for us, since they play a key role in the development and function of cortico-thalamic-striatal circuits contributing to efficient motor planning and execution (Fisher and Scharff, 2009; Schreiweis et al., 2014). Interestingly, some of these proteins function in conjunction with ROBOs and SLITs (e.g., CNTNAP2) (Banerjee et al., 2010). Finally, the constellation of genes around AUTS2 is important for the establishment of intra- and interhemispheric connectivity and in particular, of an optimal balance between excitation and inhibition, which seems to be also impaired in autism (Just et al., 2004; Yizhar et al., 2011; Zikopoulos and Barbas, 2013).

Returning to our initial concern of the heterogeneity, variability, and specifically, comorbidity between motor and cognitive disorders observed in ASD, this frequent outcome of research and of clinical practice may be explained by the fact that the three set of genes we highlight here, involved in different aspects of cognition and motor behavior, are functionally interconnected. For example, as we mentioned earlier, some people suffering from autism bear a defective copy of TBR1. Specifically, disruptions of TBR1 give rise to severe speech and language deficits, autistic problems, and moderate to severe intellectual disability (Palumbo et al., 2014). This complex, comorbid phenotype may be partially explained by the molecular interactions TBR1 is involved in. To begin with, TBR1 interacts with FOXP2 (Deriziotis et al., 2014), which is relevant for the externalization of language. Moreover, TBR1 seems to act as a master regulator controlling several other ASD-candidate genes (Chuang et al., 2015), including AUTS2 (Bedogni et al., 2010). Among Auts2 regulators we find both Runx2 and Foxp2 (Oksenberg et al., 2014), which are central pieces of our networks. At the brain level TBR1 contributes to the establishment of neocortical connectivity with the thalamus (McKenna et al., 2011), but also of interhemispheric connections involving callosal axons (Hevner et al., 2001). Importantly, the integrity of the corpus callosum is frequently reported to be affected in people suffering from ASD (Kumar et al., 2010; Shukla et al., 2010). Similarly, a decrease in interhemispheric connections seems to be a hallmark of this condition (Shukla et al., 2010; Ingalhalikar et al., 2011). Lastly, in mice Tbr1 haploinsufficiency also results in defective axonal projections of amygdalar neurons, which give rise to a deficit in ultrasonic vocalization, social interaction, and associative memory and cognitive flexibility (Huang et al., 2014).

It is also of interest that many of the genes we have focused on have changed after our split from Neanderthals and Denisovans (see Boeckx and Benítez-Burraco, 2014a,b; Benítez-Burraco 
and Boeckx, submitted for details). It has been hypothesized that recently evolved neuronal networks are more sensitive to damage because they are endowed with less robust compensatory mechanisms (Toro et al., 2010). As a consequence, perturbations affecting them (e.g., mutations in specific genes) are expected to impair their development more easily and more frequently. This could account for the high prevalence of autism within modern human populations (according to Gibson, 2009 disorders like ASD are de-canalized conditions, resulting from the uncovering of cryptic genetic variation as a consequence of genomic, environmental, or even cultural perturbations).

In sum, we regard the motor approach to language dysfunction in autism of outstanding interest for autism research, but

\section{References}

Alarcón, M., Abrahams, B. S., Stone, J. L., Duvall, J. A., Perederiy, J. V., Bomar, J. M., et al. (2008). Linkage, association, and gene-expression analyses identify CNTNAP2 as an autism-susceptibility gene. Am. J. Hum. Genet. 82, 150-159. doi: 10.1016/j.ajhg.2007.09.005

Banerjee, S., Blauth, K., Peters, K., Rogers, S. L., Fanning, A. S., and Bhat, M. A. (2010). Drosophila neurexin IV interacts with Roundabout and is required for repulsive midline axon guidance. J. Neurosci. 30, 5653-5667. doi: 10.1523/JNEUROSCI.6187-09.2010

Bedogni, F., Hodge, R. D., Elsen, G. E., Nelson, B. R., Daza, R. A., Beyer, R. P., et al. (2010). Tbr1 regulates regional and laminar identity of postmitotic neurons in developing neocortex. Proc. Natl. Acad. Sci. U.S.A. 107, 13129-13134. doi: 10.1073/pnas.1002285107

Belmonte, M. K., Saxena-Chandhok, T., Cherian, R., Muneer, R., George, L., and Karanth, P. (2013). Oral motor deficits in speech-impaired children with autism. Front. Integr. Neurosci. 7:47. doi: 10.3389/fnint.2013. 00047

Boeckx, C., and Benítez-Burraco, A. (2014a). The shape of the human languageready brain. Front. Psychol. 5:282. doi: 10.3389/fpsyg.2014.00282

Boeckx, C., and Benítez-Burraco, A. (2014b). Globularity and language-readiness: generating new predictions by expanding the set of genes of interest. Front. Psychol. 5:1324. doi: 10.3389/fpsyg.2014.01324

Butler, M. G., Dasouki, M. J., Zhou, X.-P., Talebizadeh, Z., Brown, M., Takahashi, T. N., et al. (2005). Subset of individuals with autism spectrum disorders and extreme macrocephaly associated with germline PTEN tumour suppressor gene mutations. J. Med. Genet. 42, 318-321. doi: 10.1136/jmg.2004.024646

Cheung, C., McAlonan, G. M., Fung, Y. Y., Fung, G., Yu, K. K., Tai, K. S., et al. (2011). MRI study of minor physical anomaly in childhood autism implicates aberrant neurodevelopment in infancy. PLoS ONE 6:e20246. doi: 10.1371/journal.pone.0020246

Chuang, H. C., Huang, T. N., and Hsueh, Y. P. (2015). T-Brain-1-a potential master regulator in autism spectrum disorders. Autism Res. doi: 10.1002/aur.1456. [Epub ahead of print].

Comings, D. E., Wu, S., Chiu, C., Muhleman, D., and Sverd, J. (1996). Studies of the c-Harvey-Ras gene in psychiatric disorders. Psychiatry Res. 63, 25-32. doi: 10.1016/0165-1781(96)02829-6

Deriziotis, P., O’Roak, B. J., Graham, S. A., Estruch, S. B., Dimitropoulou, D., Bernier, R. A., et al. (2014). De novo TBR1 mutations in sporadic autism disrupt protein functions. Nat. Commun. 5, 4954. doi: 10.1038/ncomms5954

De Rubeis, S., He, X., Goldberg, A., Poultney, C., Samocha, K., Ercument, C., et al. (2014). Synaptic, transcriptional and chromatin genes disrupted in autism. Nature. 515, 209-215. doi: 10.1038/nature 13772

Di Cristo, G. (2007). Development of cortical GABAergic circuits and its implications for neurodevelopmental disorders. Clin. Genet. 72, 1-8. doi: 10.1111/j.1399-0004.2007.00822.x

Esposito, G., and Paşca, S. P. (2013). Motor abnormalities as a putative endophenotype for Autism spectrum disorders. Front. Integr. Neurosci. 7:43. doi: 10.3389/fnint.2013.00043 also for our understanding of the biological nature of the human faculty for language. We believe that the genetic aspects highlighted here may contribute to gain a better understanding of the way in which cognitive and motor behaviors affect each other in people with ASD.

\section{Acknowledgments}

Preparation of this work was supported in part by funds from the Spanish Ministry of Economy and Competitiveness (grant number FFI-2013-43823-P). We thank Constantina Theofanopoulou for comments, especially concerning the role of thalamus and of the corpus callosum.

Fisher, S. E., and Scharff, C. (2009). FOXP2 as a molecular window into speech and language. Trends Genet. 25, 166-177. doi: 10.1016/j.tig.2009.03.002

Gibson, G. (2009). Decanalization and the origin of complex disease. Nat. Rev. Genet. 10, 134-140. doi: 10.1038/nrg2502

Hamdan, F. F., Daoud, H., Rochefort, D., Piton, A., Gauthier, J., Langlois, M. et al. (2010). De novo mutations in FOXP1 in cases with intellectual disability, autism, and language impairment. Am. J. Hum. Genet. 87, 671-678. doi: 10.1016/j.ajhg.2010.09.017

Hevner, R., Shi, L., Justice, N., Hsueh, Y., Sheng, M., Smiga, S., et al. (2001). Tbr1 regulates differentiation of the preplate and layer 6. Neuron 29, 353-366. doi: 10.1016/S0896-6273(01)00211-2

Hickok, G., and Poeppel, D. (2007). The cortical organization of speech processing. Nat. Rev. Neurosci. 8, 393-402. doi: 10.1038/nrn2113

Huang, T. N., Chuang, H. C., Chou, W. H., Chen, C. Y., Wang, H. F., Chou, S. J., et al. (2014). Tbrl haploinsufficiency impairs amygdalar axonal projections and results in cognitive abnormality. Nat. Neurosci. 17, 240-247. doi $10.1038 / \mathrm{nn} .3626$

Ingalhalikar, M., Parker, D., Bloy, L., Roberts, T. P., and Verma, R. (2011). Diffusion based abnormality markers of pathology: toward learned diagnostic prediction of ASD. Neuroimage 57, 918-927. doi: 10.1016/j.neuroimage.2011.05.023

Jeremy Willsey, A., and State, M. W. (2014). Autism spectrum disorders: from genes to neurobiology. Curr. Opin. Neurobiol. 30, 92-99. doi: 10.1016/j.conb.2014.10.015

Jeste, S. S., and Geschwind, D. H. (2014). Disentangling the heterogeneity of autism spectrum disorder through genetic findings. Nat. Rev. Neurol. 10, 74-81. doi: 10.1038/nrneurol.2013.278

Just, M. A., Cherkassky, V. L., Keller, T. A., and Minshew, N. J. (2004). Cortical activation and synchronization during sentence comprehension in highfunctioning autism: evidence of underconnectivity. Brain 127, 1811-1821. doi: 10.1093/brain/awh199

Kumar, A., Sundaram, S. K., Sivaswamy, L., Behen, M. E., Makki, M. I., Ager, J., et al. (2010). Alterations in frontal lobe tracts and corpus callosum in young children with autism spectrum disorder. Cereb. Cortex 20, 2103-2113. doi: 10.1093/cercor/bhp278

Kwan, K. Y. (2013). Transcriptional dysregulation of neocortical circuit assembly in ASD. Int. Rev. Neurobiol. 113, 167-205. doi: 10.1016/B978-0-12-4187009.00006-X

Lin, M., Pedrosa, E., Shah, A., Hrabovsky, A., Maqbool, S., Zheng, D., et al. (2011). RNA-Seq of human neurons derived from iPS cells reveals candidate long noncoding RNAs involved in neurogenesis and neuropsychiatric disorders. PLoS ONE 6:e23356. doi: 10.1371/journal.pone.0023356

Liu, X., Novosedlik, N., Wang, A., Hudson, M. L., Cohen, I. L., Chudley, A. E., et al. (2009). The DLX1and DLX2 genes and susceptibility to autism spectrum disorders. Eur. J. Hum. Genet. 17, 228-235. doi: 10.1038/ejhg.2008.148

Maekawa, M., Iwayama, Y., Nakamura, K., Sato, M., Toyota, T., Ohnishi, T., et al. (2009). A novel missense mutation (Leu46Val) of PAX6 found in an autistic patient. Neurosci. Lett. 462, 267-271. doi: 10.1016/j.neulet.2009.07.021

McKenna, W. L., Betancourt, J., Larkin, K. A., Abrams, B., Guo, C., Rubenstein, J. L., et al. (2011). Tbr1 and Fezf2 regulate alternate corticofugal 
neuronal identities during neocortical development. J. Neurosci. 31, 549-564. doi: 10.1523/JNEUROSCI.4131-10.2011

Miller, E. K., and Buschman, T. J. (2007). "Rules through recursion: how interactions between the frontal cortex and basal ganglia may build abstract, complex, rules from concrete, simple, ones," in The Neuroscience of Rule-Guided Behavior, eds S. Bunge and J. Wallis (Oxford: Oxford University Press), 419-440.

Murphy, C. M., Christakou, A., Daly, E. M., Ecker, C., Giampietro, V., Brammer, M., et al. (2014). Abnormal functional activation and maturation of fronto-striato-temporal and cerebellar regions during sustained attention in autism spectrum disorder. Am. J. Psychiatry 171, 1107-1116. doi: 10.1176/appi.ajp.2014.12030352

Nair, A., Treiber, J. M., Shukla, D. K., Shih, P., and Müller, R. A. (2013). Impaired thalamocortical connectivity in autism spectrum disorder: a study of functional and anatomical connectivity. Brain 136, 1942-1955. doi: 10.1093/brain/awt079

Nakashima, N., Yamagata, T., Mori, M., Kuwajima, M., Suwa, K., and Momoi, M. Y. (2010). Expression analysis and mutation detection of DLX5 and DLX6 in autism. Brain Dev. 32, 98-104. doi: 10.1016/j.braindev.2008.12.021

Naqvi, S., Cole, T., and Graham, J. M. Jr. (2000). Cole-Hughes macrocephaly syndrome and associated autistic manifestations. Am. J. Med. Genet. 94, 149-152. doi: 10.1002/1096-8628(20000911)94:2<149::AID-AJMG7>3.0.CO;2-\#

Oksenberg, N., and Ahituv, N. (2013). The role of AUTS2 in neurodevelopment and human evolution. Trends Genet. 29, 600-608. doi: 10.1016/j.tig.2013.08.001

Oksenberg, N., Haliburton, G. D., Eckalbar, W. L., Oren, I., Nishizaki, S., Murphy, K., et al. (2014). Genome-wide distribution of Auts2 binding localizes with active neurodevelopmental genes. Transl. Psychiatry 4, e431. doi: $10.1038 /$ tp. 2014.78

O’Roak, B. J., Vives, L., Girirajan, S., Karakoc, E., Krumm, N., Coe, B. P., et al. (2012). Sporadic autism exomes reveal a highly interconnected protein network of de novo mutations. Nature 485, 246-250. doi: 10.1038/nature10989

Palumbo, O., Fichera, M., Palumbo, P., Rizzo, R., Mazzolla, E., Cocuzza, D. M., et al. (2014). TBR1 is the candidate gene for intellectual disability in patients with a 2q24.2 interstitial deletion. Am. J. Med. Genet. A 164A, 828-833. doi: 10.1002/ajmg.a.36363

Petkov, C., and Jarvis, E. D. (2012). Birds, primates, and spoken language origins: behavioral phenotypes and neurobiological substrates. Front. Evol. Neurosci. 4:12. doi: $10.3389 /$ fnevo. 2012.00012

Pfenning, A. R., Hara, E., Whitney, O., Rivas, M. V., Wang, R., Roulhac, P. L., et al. (2014). Convergent transcriptional specializations in the brains of humans and song-learning birds. Science 346:1256846. doi: 10.1126/science.1256846

Schreiweis, C., Bornschein, U., Burguière, E., Kerimoglu, C., Schreiter, S., Dannemann, M., et al. (2014). Humanized Foxp2 accelerates learning by enhancing transitions from declarative to procedural performance. Proc. Natl. Acad. Sci. U.S.A. 111, 14253-14258. doi: 10.1073/pnas.1414542111

Shukla, D. K., Keehn, B., Lincoln, A. J., and Müller, R. A. (2010). White matter compromise of callosal and subcortical fiber tracts in children with autism spectrum disorder: a diffusion tensor imaging study. J. Am. Acad. Child Adolesc. Psychiatry 49, 1269-1278. doi: 10.1016/j.jaac.2010.08.018

Suda, S., Iwata, K., Shimmura, C., Kameno, Y., Anitha, A., Thanseem, I., et al. (2011). Decreased expression of axon-guidance receptors in the anterior cingulate cortex in autism. Mol. Autism. 2:14. doi: 10.1186/2040-2392-2-14

Tager-Flusberg, H., Paul, R., and Lord, C. (2005). "Language and communication in autism," in Handbook of Autism and Pervasive Developmental Disorders, eds F. R. Volkmar, R. Paul, A. Klin, and D. Cohen (New York, NY: Wiley), 335-364.

Toro, R., Konyukh, M., Delorme, R., Leblond, C., Chaste, P., Fauchereau, F., et al. (2010). Key role for gene dosage and synaptic homeostasis in autism spectrum disorders. Trends Genet. 26, 363-372. doi: 10.1016/j.tig.2010.05.007

Wang, K., Zhang, H., Ma, D., Bucan, M., Glessner, J. T., Abrahams, B. S., et al. (2009). Common genetic variants on 5p14.1 associate with autism spectrum disorders. Nature 459, 528-533. doi: 10.1038/nature07999

Wang, R., Chen, C. C., Hara, E., Rivas, M. V., Roulhac, P. L., Howard, J. T. et al. (2015). Convergent differential regulation of SLIT-ROBO axon guidance genes in the brains of vocal learners. J. Comp. Neurol. 52, 892-906. doi: $10.1002 /$ cne. 23719

Yizhar, O., Fenno, L. E., Prigge, M., Schneider, F., Davidson, T. J., O'Shea, D. J., et al. (2011). Neocortical excitation/inhibition balance in information processing and social dysfunction. Nature 477, 171-178. doi: 10.1038/nature 10360

Zikopoulos, B., and Barbas, H. (2013). Altered neural connectivity in excitatory and inhibitory cortical circuits in autism. Front. Hum. Neurosci. 7:609. doi: 10.3389/fnhum.2013.00609

Conflict of Interest Statement: The authors declare that the research was conducted in the absence of any commercial or financial relationships that could be construed as a potential conflict of interest.

Copyright (c) 2015 Benitez-Burraco and Boeckx. This is an open-access article distributed under the terms of the Creative Commons Attribution License (CC BY). The use, distribution or reproduction in other forums is permitted, provided the original author(s) or licensor are credited and that the original publication in this journal is cited, in accordance with accepted academic practice. No use, distribution or reproduction is permitted which does not comply with these terms. 